\title{
Penile Cancer Management in the United States: Regional Centers of Expertise are Needed!
}

\author{
Curtis A. Pettaway, MD \\ The University of Texas M.D. Anderson Cancer Center, Houston, TX
}

High-risk, invasive, penile squamous primary tumors are associated with an elevated risk of occult regional lymph node metastases and include high-stage or highgrade tumors and those exhibiting lymph vascular invasion. ${ }^{1-3}$ In fact, among stage $\mathrm{T} 1$ tumors (i.e., without involvement of corpora spongiosum or cavernosum) highgrade and LVI+ tumors were recognized as a distinct entity in the 7th edition of the American Joint Committee on Cancer (AJCC) Staging System in 2010 and designated as stage $\mathrm{T} 1 \mathrm{~b} .{ }^{4} \mathrm{~A}$ recent study documented an elevated risk of inguinal metastases among T1b tumors with an incidence that is similar to $\geq$ stage T2 primary tumors. ${ }^{3}$ Given these data and retrospective series suggesting improved outcome among men with high-risk primary tumors (cN0) undergoing early versus delayed surgical staging, guideline groups have recommended inguinal staging, termed surgical lymph node evaluation (SLNE by the authors) among cN0 patients with high-risk primary tumors. ${ }^{5-7}$ Despite these recommendations, utilization of SLNE remains low. Two different studies have estimated that only between 18-26\% of high-risk patients in the United States undergo any form of inguinal evaluation. ${ }^{8,9}$

The current study by Zhu et al. in this issue of the journal is informative in this regard, because it evaluates penile cancer patients in two tertiary care academic centers, as well as the SEER population in the United States, and describes the use of SLNE with a focus on the T1b group of patients. ${ }^{10}$ The incidence of metastases and survival in both cohorts is described as a function of primary tumor stage. As noted by the authors, the two academic cohorts

(C) Society of Surgical Oncology 2019

First Received: 2 January 2019;

Published Online: 25 January 2019

C. A. Pettaway, MD

e-mail: cpettawa@mdanderson.org exhibited a higher incidence of high-risk penile tumors, including those of stage T1b. Among these two specialized centers, surgical lymph node evaluation (SLNE) was performed in $73 \%$ of patients with high-risk primary tumors, including $100 \%$ of the T1b subset undergoing SLNE. In the SEER cohort, $2.8-48 \%$ of patients with high-risk tumors underwent SLNE with only $21.7 \%$ of patients with stage T1b primary tumors undergoing SLNE. Given guideline group recommendations, it is clear that SLNE is underutilized in the U.S. population among all patients with invasive penile primary tumors. ${ }^{6,7}$ The significance of this finding is shown in both the academic and populationbased data; among both groups the T1b subset of patients exhibited a higher incidence of nodal metastases and penile cancer-specific death compared with stage-T1a patients. Furthermore, among the SEER patients who were clinically node-negative while the risk of nonpenile cancer death was similar for T1b versus T1a patients, the risk of dying of penile cancer was substantially higher for the T1b cohort. This is relevant, because most of the SEER cohort did not undergo SLNE.

It is unfortunate that these data not only reinforce that penile cancer patients with invasive primary tumors are poorly managed at the population level in the United States but that the result of this mismanagement could lead to an increased risk of death from penile cancer. Given the rarity of penile cancer, these data should provide further impetus for the regionalization of penile cancer care with the development of centers of expertise. A model for this has been successfully implemented and validated in the United Kingdom. ${ }^{10}$

\section{REFERENCES}

1. Slaton JW, Morgenstern N, Levy DA, et al. Tumor stage, vascular invasion, and the percentage of poorly differentiated cancer: independent prognosticators for inguinal lymph node metastasis in penile squamous carcinoma. J Urol. 2001;165(4):1138-1142. 
2. Graafland NM, Lam W, Leijte JA, et al. Prognostic factors for occult inguinal lymph node involvement in penile carcinoma and assessment of the high-risk EAU subgroup: a two-institution analysis of 342 clinically node-negative patients. Eur Urol. 2010;58(5):742-747.

3. Sun M, Djajadiningrat RS, Alnajar HM, et al. Development and external validation of a prognostic tool for prediction of cancerspecific mortality after complete locoregional pathological staging for squamous cell carcinoma of the penis. BJU Int Eur Urol. 2015;67:142-150.

4. Edge SB, Byrd DR, Compton CC, et al. Penis. AJCC Cancer Staging Manual, 7th edn. New York: Springer; 2010.

5. Kroon BK, Horenblas S, Lont AP, et al. Patients with penile carcinoma benefit from immediate resection of clinically occult lymph node metastases. J Urol. 2005;173:816-819.

6. Hakenberg OW, Comperat EM, Minhas S, et al. EAU guidelines on penile cancer: 2014 update. Eur Urol. 2015;67(1)142-150.

7. NCCN Clinical Practice Guidelines in Oncology: Penile cancer V3.2015. http://www.nccn.org/professionals/physician_gls/pdf/p enile.pdf.
8. Johnson TV, Hsiao W, Delman KA, et al. Extensive inguinal lymphadenectomy improves overall 5-year survival in penile cancer patients: results from the Surveillance, Epidemiology, and End Results program. Cancer. 2010;116(12):2960-2966.

9. Chipolini J, Tang D, Gilbert SM, et al. Delay to inguinal lymph node dissection greater than 3 months predicts poorer recurrencefree survival for patients with penile cancer. $J$ Urol. 2017;198(6):1346-1352.

10. Veeeratterapillay R, Teo L, Asterling S, Greene D. Oncologic outcomes of penile cancer treatment at a UK supraregional center. Urology. 2015;85:1097-1103

Publisher's Note Springer Nature remains neutral with regard to jurisdictional claims in published maps and institutional affiliations. 